\title{
The search for sustainable parameters for steel- reinforced concrete section of a bridge superstructure
}

\author{
Yuriy $\mathrm{Krul}^{1, *}$, and Roman Kaplin ${ }^{2}$ \\ ${ }^{1}$ Kharkiv National Automobile and Highway University, 61002 Yaroslava Mudrogo str, 25, Kharkiv, \\ Ukraine \\ 2 Hon. Prof. M. S. Bokarius Kharkiv Research Institute of Forensic Examinations, 61117 \\ Zolochevskaya str, 8a, Kharkiv, Ukraine
}

\begin{abstract}
The article contains the description of an efficient lightweight steel-reinforced concrete bridge superstructure, which includes metal blocks with a box-like section and reinforced concrete efficient roadway slab. Metal blocks are made of sheet perforated elements manufactured according to the no-waste technology. The blocks are interconnected as a single space bridge superstructure frame by means of high strength bolts. The reinforced concrete slab of the roadway is an efficient hollow slab. It includes upper and lower housing, inner ribs placed with a particular pitch, and all its remained part is filled with polystyrene foam extractable fillers along its height. At this, a rib height is equal to the full slab height. The metal and reinforced concrete parts are linked by means of a special system of shearing connections. The article describes an iteration algorithm of the construction enhancement, in course of which the geometrical parameters, such as bridge superstructure section full height, reinforced concrete slab thickness and a construction metal part height were defined. Theoretical models being the ground for the strain-stress state (SSS) of the sections studied analysis were developed.
\end{abstract}

\section{Introduction}

Steel-reinforced concrete bridge superstructures have become the up-to-date bridge structures widely applied worldwide [1-3]. The principle advantage of steel-reinforced concrete structures is the diminished dead weight in comparison with reinforced concrete systems as well as the dipped steel consumption and the resulted decrease in an initial cost comparing to metal bridge superstructures. These systems are the most sustainable at spans of 40-80 m [4]. One of the conditions to widen the range of use of steel-reinforced concrete bridge superstructures (firstly, according to the size of spans) is the diminished dead weight of a structure at a specified bearing capacity. This fact encourages searching for new efficient lightweight structures of steel-reinforced concrete bridge superstructures, whose

\footnotetext{
*Corresponding author: krul.yuriy@gmail.com
} 
characteristics would be enhanced in comparison with fully reinforced concrete and steel systems.

\section{Structural peculiarities}

In connection with stated above, the modular two-component system of lightweight steelreinforced concrete shell-type bridge superstructures was suggested [5]. The structure consists of metal blocks with box-like sections and an efficient lightweight reinforced concrete roadway slab put into operation by means of the shearing connections system (fig.1).

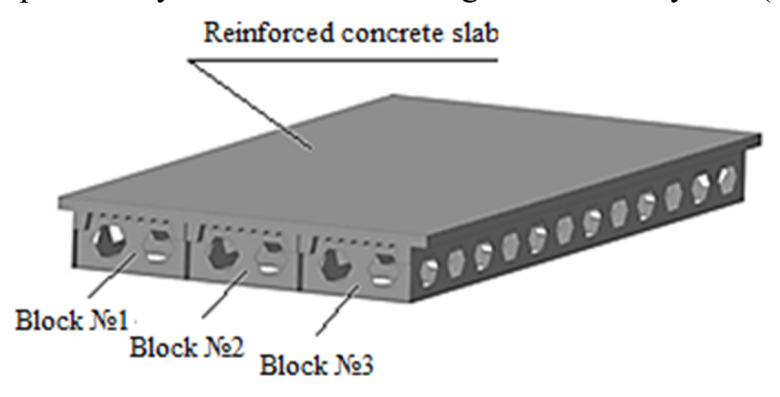

Fig. 1. The fragment of a suggested steel-reinforced concrete bridge superstructure.

Metal blocks are made of perforated sheet elements manufactured according to the nowaste technology. The block consists of two main bars, a lower metal plate connecting main bars and transverse membranes mounted with the calculated pitch according to the span length (Fig. 2).

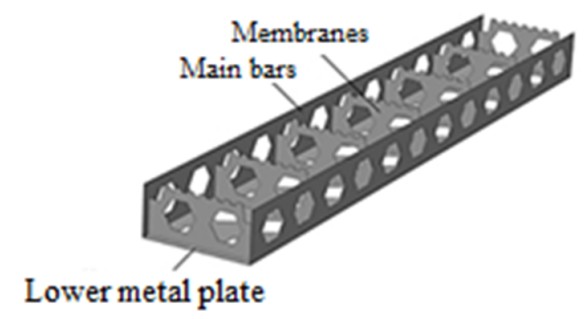

Fig. 2. Metal block of the steel-reinforced concrete bridge superstructure.

Metal bars, in turn, can be manufactured either with an upper horizontal shelf being a supporting element for the reinforced concrete slab, or without it. The blocks are interconnected as a single space bridge superstructure frame by means of high strength bolts (Fig. 3).

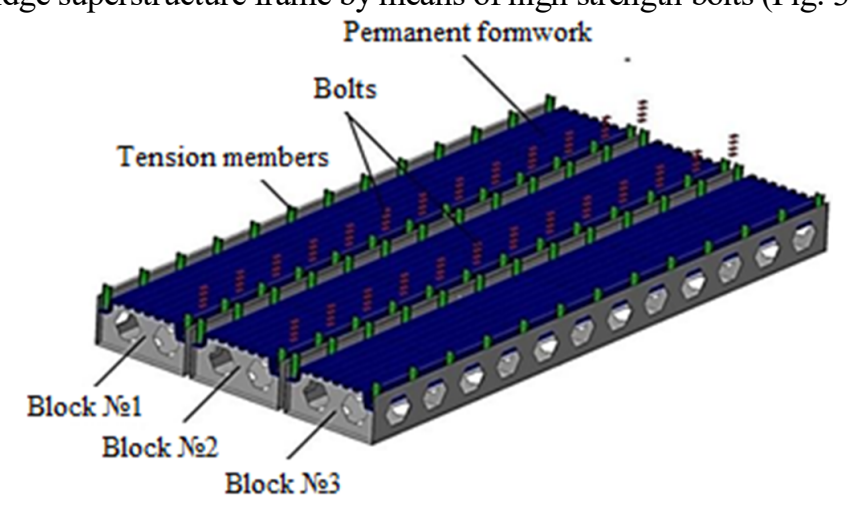

Fig. 3. Interconnection of blocks by means of high strength bolts. 
A graded steel sheet is placed over the block membranes. It is a retained form for the reinforced concrete slab. The reinforced concrete slab of the roadway is an efficient hollow slab. It includes upper and lower housing, inner ribs placed with a particular pitch, and its entire remained part is filled with polystyrene foam extractable fillers along its height. Thus, a rib height is equal to the full slab height (Fig. 4).

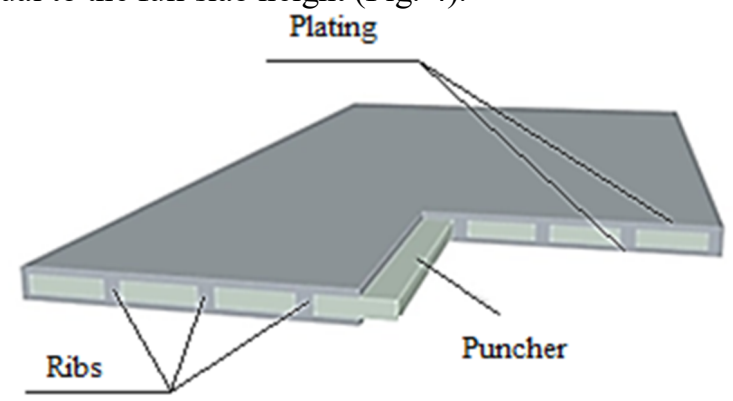

Fig. 4. The roadway slab construction.

To provide joint operation of the metal part with the reinforced concrete slab the system of discrete-and-continual shear connections in the form of dead stops jointed at the transverse and longitudinal directions with deformed section steel bars jointed with the slab reinforcement cage was suggested (fig. 5).

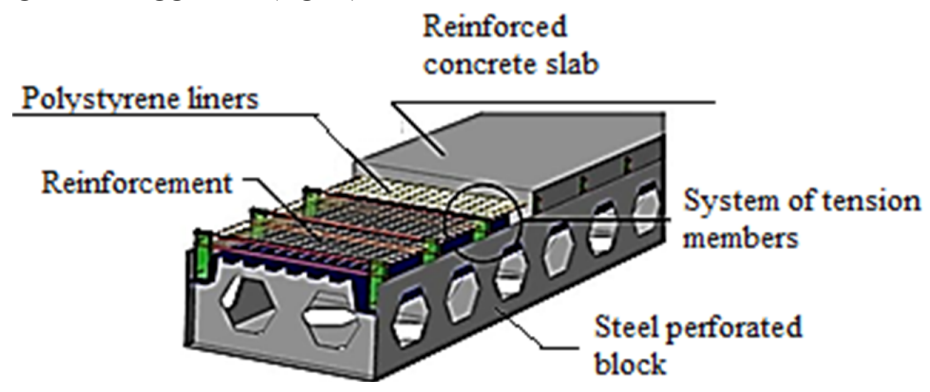

Fig. 5. The system of discrete-and-continual shear connections. General view.

\section{Problem statement}

The article [6] suggests determining a minimum height of the metal perforated bar on the ground of necessary toughness conditions by the following formula:

$$
h=2 \cdot \beta \cdot \frac{\sigma}{E} \cdot\left[\frac{l}{f}\right] \cdot l
$$

where $\sigma$-calculated steel resistance; $E$ - steel deflection module; $f$ - allowed standard sag; $l$ - bar span.

It is recommended to adopt the T-bar belt height in compliance with [4] as follows: $h_{f}=h / 4$

The guaranteed inclusion of a reinforced concrete slab into joint operation allows decreasing the metal part height, which results in shrinking of the studied section full height. The following solution to the given problem is suggested to determine the reinforced concrete slab application efficiency: to compare characteristics of metal perforated bar and steel-reinforced concrete section of the bridge superstructure fragment. 


\section{Hypothesis and assumptions}

An algorithm to determine the optimal section height of the bridge superstructure and the impact of the reinforced concrete slab on the height of metal part of the structure was suggested within the stated design solution. For this purpose, a fragment is extracted from the shell. It is a metal perforated two-T-bar with the efficient reinforced concrete slab placed on the upper shelf of the bar (Fig. 6).

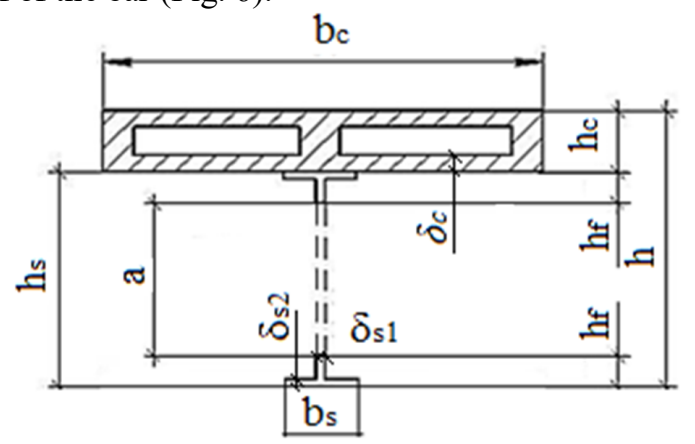

Fig. 6. Transverse section of the bridge superstructure fragment.

We introduce parameters vector [7,8,9], which describe the suggested steel-reinforced concrete section:

$$
\{X\}^{T}=\left\{h, h_{s}, h_{f}, \delta_{s 1}, \delta_{s 2}, \delta_{c}, h_{c}, a, b_{c}, b_{s}\right\}
$$

where $h$ - full section height; $h_{s}$ - metal perforated part section height; $h_{f}$ - height of Tbar belt of the metal perforated part section; $\delta_{s 1}$ - wall thickness of metal perforated part section; $\delta_{s 2}-$ metal perforated part section shelf thickness; $\delta_{c}$ - housing thickness of reinforced concrete part section; $a$ - hole height of metal perforated part section; $b_{s}-$ shelf width of metal perforated part section; $h_{c}$ - thickness of reinforced concrete part section; $b_{c}$ - width of reinforced concrete part section (bar pitch).

We adopt several assumptions during calculations:

-the suggested system of shearing connections is assumed to provide joint operation of metal and reinforced concrete parts section that allows considering the given fragment integrally;

- at this, at limit state it is adopted that the reinforced concrete part section is in the compressive side, while metal part is in the tensile one. This allows assuming that the neutral axis comes along the boarder of the metal bar connection with the reinforced concrete slab.

\section{Calculations procedure}

Studying the metal two-T-bar by formula (1), we determine a minimum bar height on the basis of necessary toughness conditions. We further determine several geometric characteristics for the metal bar: 


$$
\left\{\begin{array}{l}
A_{1}=b \cdot \delta_{1} \cdot 2+\left(h_{f}-\delta_{1}\right) \cdot \delta_{2} \cdot 2 \\
S_{1}=b \cdot \delta_{1} \cdot\left(h-\frac{\delta_{1}}{2}\right)+\left(h_{f}-\delta_{1}\right) \cdot \delta_{2} \cdot\left(h-\frac{h_{f}-\delta_{1}}{2}\right)+\left(h_{f}-\delta_{1}\right) \cdot \delta_{2} \cdot\left(\frac{h_{f}-\delta_{1}}{2}+\delta_{1}\right)+b \cdot \delta_{1} \cdot\left(\frac{\delta_{1}}{2}\right) \\
y_{1}^{*}=\frac{S_{z}}{A} \\
J_{1}=2 \cdot\left(\frac{b \cdot \delta_{1}^{3}}{12}+\frac{\delta_{2} \cdot\left(h_{f}-\delta_{1}\right)^{3}}{12}+b \cdot \delta_{1} \cdot\left(h-\frac{\delta_{1}}{2}-y^{*}\right)^{2}+\delta_{2} \cdot h_{f} \cdot\left(h-\frac{h_{f}-\delta_{1}}{2}-y^{*}\right)^{2}\right) \\
W_{1}=J_{z 1} \cdot 2 / h
\end{array}\right.
$$

where $A_{1}$ - metal cross-sectional area; $S_{1}$ - first moment of the area of metal section; $y_{1}^{*}-$ metal section gravity center; $J_{1}-$ second moment of the metal section; $W_{1}$ - sideway moment of metal section resistance.

We determine the metal bar bearing capacity by the following formula:

$$
M_{U S}=R_{S} \cdot W_{P L}
$$

where $R_{S}$ - calculated steel resistance; $W_{P L}$ - elastic-plastic moment of section resistance.

It can be determined as follows:

$$
W_{P L}=\gamma \cdot W
$$

where $\gamma=1,25 \ldots 2,0$ (depends on the section shape and is to be determined by means of manual tables).

We further study the steel-reinforced concrete fragment section. To simplify calculations, we substitute the efficient reinforced concrete slab with the reinforced concrete slab with an effective thickness (Fig. 7).

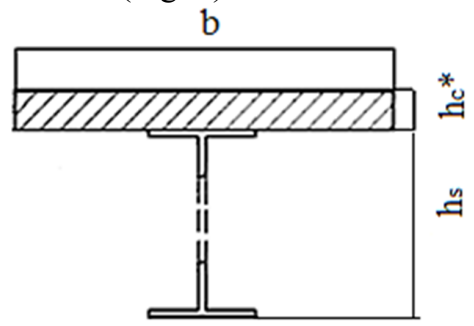

Fig. 7. Transverse section of the steel-reinforced concrete fragment with the effective reinforced concrete slab.

Determination of the effective slab thickness is made on the ground of section toughness equality. Since reinforced concrete consumption for slabs is equal, second moment of the section must coincide:

$$
J_{2}=J_{2}^{*}
$$

where $J_{2}$ - second moment of the section with the efficient reinforced concrete slab; $J_{2}^{*}-$ section second moment with the effective slab.

Based on the above, an expected diagram of tensions is demonstrated in Fig. 8. 


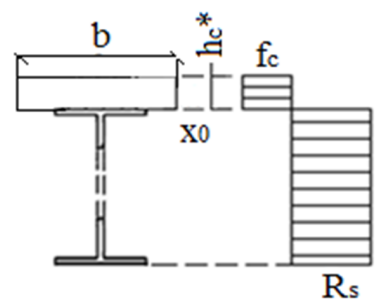

Fig. 8. Diagram of tensions of a steel-reinforced concrete element (limit state).

The hypothesis introduced above permits the following equation for limit balance:

$$
b_{c}^{r e d} \cdot h_{c}^{*} \cdot f_{c}-A_{s} \sigma_{y s}=0
$$

Based on (6), effective equivalent constituent thickness of the reinforced concrete slab is equal to:

$$
h_{c}^{*}=\frac{A_{s} \cdot R_{s}}{b_{c}^{r e d} \cdot f_{c}}
$$

The following stage of calculation is to perform constructive reduction to a single material. For this we apply reduction factor method. After this operation, the metal bar section with the equivalent constituent reflecting reinforced concrete slab at the upper belt will become equal in strength with metal two-T-bar with the efficient hollow reinforced concrete slab (Fig. 9).

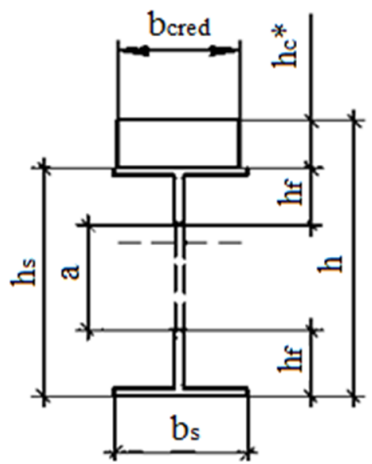

Fig. 9. Section with the equivalent constituent, reflecting reinforced concrete slab.

Considering that the metal bar and section with the equivalent constituent, reflecting reinforced concrete slab, we take them as equivalent, and they must have equal toughness, i.e. the condition must be performed (8):

$$
J_{2}^{* \text { red }}=J_{1}
$$

where $J_{1}$ - metal section second moment; $J_{2}^{* \text { red }}$ - section second moment with the equivalent constituent, reflecting reinforced concrete slab.

Equation for section second moment with the equivalent constituent, reflecting reinforced concrete slab: 


$$
\begin{aligned}
& J_{2}^{r e d}=\frac{b_{c}^{\text {red }} \cdot h_{c}^{* 3}}{12}+\left(\frac{b_{s} \cdot \delta_{1}^{3}}{12}\right) \cdot 2+\frac{\delta_{1} \cdot\left(h_{f}-2 \cdot \delta_{2}\right)^{3}}{12}+b_{c}^{\text {red }} \cdot h_{c}^{*} \cdot\left(h_{s}-\frac{h_{c}}{2}-y_{2}^{*}\right)^{2}+ \\
& +b_{1} \cdot \delta_{2} \cdot\left(h_{s}-\frac{\delta_{2}}{2}-y_{2}^{*}\right)^{2}+\delta_{1} \cdot\left(h_{s}-2 \cdot \delta_{2}\right) \cdot\left(\frac{h_{s}}{2}-y_{2}^{*}\right)^{2}
\end{aligned}
$$

Putting expression (7) into equation (9) as well as into condition (8) we obtain the opportunity to determine height of the metal bar $h_{s}$. By obtaining the height of the metal part section and putting it into expression (7), we determine the reinforced concrete slab equivalent constituent thickness.

Condition for bearing capacity of the studied section must be filfilled in the same way:

$$
\frac{M_{U}}{M_{U S}} \geq 1
$$

where $M_{U}$ - bearing capacity of the section with the reinforced concrete slab equivalent constituent; $M_{U S}$ - bearing capacity of the reinforced concrete slab.

Bearing capacity of the section with the reinforced concrete slab equivalent constituent is equal to:

$$
M_{U}=b \cdot h_{c} \cdot f_{c} \cdot \frac{h_{c}}{2}+A_{s} \cdot \sigma_{y s} \cdot \frac{h_{s}}{2}
$$

In case of non-fulfillment of one of conditions (8) and (10), gradual rise in reinforced concrete slab thickness will be taking place until each condition is fulfilled.

We would like to give an example of calculation of a fragment of the steel-reinforced concrete bridge superstructure. The studied construction fragment is considered to have preliminary agreed parameters, namely:

- $\quad$ span length $L=24 \mathrm{~m}$;

- allowed structural deflection $f=1 / 400 L=60 \mathrm{~mm}$;

- reinforced concrete part section made of concrete $\mathrm{C} 30 / 35$;

- metal part section made of steel 15HSND;

- slab roughness ribs placed with the $1 \mathrm{~m}$ pitch. Accepted rib thickness is $100 \mathrm{~mm}$;

- upper and lower housing with $50 \mathrm{~mm}$ thickness;

- two-T-bar shelves with $300 \mathrm{~mm}$ width and $14 \mathrm{~mm}$ thickness;

- two-T-bar wall with $12 \mathrm{~mm}$ thickness.

By putting above parameters into expression (1) we obtain minimum height of the metal perforated bar $h=1960 \mathrm{~mm}$. T-bar belt height is accepted as $h_{f}=h_{0} / 4=490$

In the result of calculations the two-T-bar section becomes like in Fig. 10.

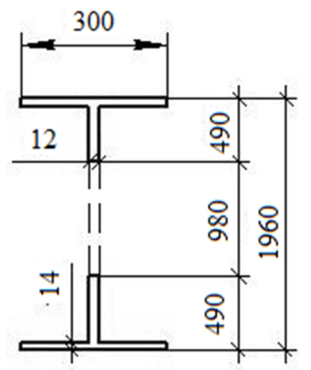

Fig. 10. Metal perforated two-T-bar. 
We determine geometric characteristics of the metal bar:

$$
\begin{gathered}
A_{1}=19820 \mathrm{~mm}^{2} \\
S_{1}=1.951 .10^{7} \mathrm{~mm}^{3} \\
J_{1}=8.177 \cdot 10^{9} \mathrm{~mm}^{4} \\
W_{1}=8.344 \cdot 10^{6} \mathrm{~mm} 3
\end{gathered}
$$

Further, we determine the metal bar height and the reinforced concrete slab equivalent constituent thickness in accordance with (7) and (8).

$$
\begin{aligned}
& h_{\mathrm{s}}=1100 \mathrm{~mm} \\
& h_{c}{ }^{*}=140 \mathrm{~mm}
\end{aligned}
$$

And by means of condition (5) we find the efficient hollow reinforced concrete slab thickness:

$$
h_{c}=300 \mathrm{~mm}
$$

The obtained transverse section of the bridge superstructure is demonstrated in Fig. 11.

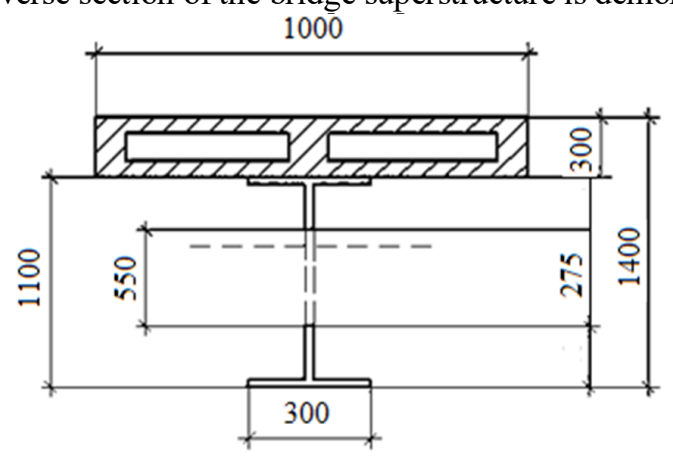

Fig. 11. Final fragment of the steel-reinforced concrete bridge superstructure.

The demonstrated formation algorithm of the efficient steel-reinforced concrete structure allows shrinking the metal bar height 1.8 times in comparison with all-metal bar. At this, the steel-reinforced concrete structure height (line meter) is $35 \%$ less than of a standard metal perforated two-T-bar. Economy is based on the reinforced concrete (nearly $1.300 \mathrm{UAH} / \mathrm{m}^{3}$ ) and steel (nearly 2.500 UAH/t) price difference. Considering the substantially lower price of the reinforced concrete, the difference in structure cost constitutes nearly $40 \%$. Due to inclusion into operation the efficient reinforced concrete slab the opportunity to dip tension in the metal part section occurs, which results in somewhat unloading the metal bar. All listed allows concluding that the suggested structure is really efficient.

Aiming at checking the suggested solution to the problem, we developed theoretical models (Fig. 12) that became the basis for conducting strain-stress state (SSS) structure analysis with determination of potential deformation energy (PDE) values.

a)

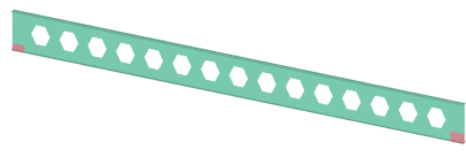

b)

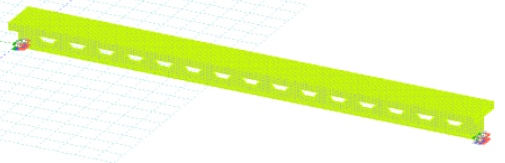

Fig. 12. Finite element models: a) of a perforated metal two-T-bar (model 1); b) of a steel-reinforced concrete section with the efficient concrete section slab (model 2).

The values obtained by the calculation are given in Table 1 . 
Table 1 Calculation results.

\begin{tabular}{|l|c|c|}
\hline \multicolumn{1}{|c|}{ Parameter } & Model 1 & Model 2 \\
\hline Potential deformation energy (PDE), $U$ & 2.505 & 2.402 \\
\hline Sag $\triangle, \mathrm{mm}$ & 5.736 & 5.730 \\
\hline Tension $N_{x}, \mathrm{MPa}$ & 1.750 & 1.610 \\
\hline Tension $N_{y}, \mathrm{MPa}$ & 4.720 & 4.630 \\
\hline Tension $\tau_{x y}, \mathrm{MPa}$ & 2.810 & 2.708 \\
\hline Free frequency $v, \mathrm{~Hz}$ & 10 & 12 \\
\hline
\end{tabular}

On the basis of the mentioned theoretical analysis we confirmed the studied constructive topology and its compliance with solidity, deformations, stability and free frequency limits.

\section{Conclusions:}

- The modular two-component system of the lightweight steel-reinforced concrete shelltype bridge superstructure was suggested.

- As a result of conducted calculations, we obtained geometrical characteristics of the steelreinforced concrete section of the suggested structure.

- We evaluated the impact of the efficient reinforced concrete slab on the height of the metal part and the height of the entire structure. This approach allows shrinking the metal bar height 1.8 times, decreasing the finite structure line meter weight by $35 \%$ and cutting the cost of used materials by $40 \%$.

- We created and analyzed two calculation models of the studied sections. At this, the discrepancy in values obtained in the course of calculation did not exceed $5 \%$.

\section{References}

1. E.E. Gibshman, Mostyi so stalnyimi balkami, ob'edinennyimi s zhelezobetonnoy plitoy (1952)

2. E.E. Gibshman, Proektirovanie stalnyih konstruktsiy, ob'edinennyih s zhelezobetonom, $v$ avtodorozhnyih mostah (1956)

3. N.N. Streletskiy, Stalezhelezobetonnyie proletnyie stroeniya mostov (1981)

4. M.M. Korneev, Stalezhelezobetonnyie mostyi: teoreticheskoe i prakticheskoe posobie po proektirovaniyu (2015)

5. Y.N. Krul, O formirovanii ratsionalnoy konstruktsii proletnogo stroeniya avtomobilnodorozhnogo mosta, Kom. Hoz. Gor. 101, 31 (2011)

6. V.V. Biryulyov, Proektirovanie metallicheskih konstruktsiy (1990)

7. G.V. Vasilkov, Evolyutsionnaya teoriya zhiznennogo tsikla mehanicheskih sistem. Teoriya sooruzheniy (2008)

8. V.S. Shmukler, Y.A. Klimov, N.P Burak, Karkasnyie sistemyi oblegchennogo tipa (2008)

9. V.M. Babaev, S.O. Bugaevskiy,S.M. Evel, I.D. Evzerov, A.I. Lantuh-Lyaschenko, V.V. Shevetovskiy, O.V. Shimanovskiy, V.S. Shmukler, Chiselni ta eksperimentalni metodi ratsionalnogo proektuvannya ta zvedennya konstruktivnih sistem (2017) 